\title{
Personal Characteristics and Selective Migration
}

By

Kjell Soderberg

University of Umeå

\section{Introduction}

Are migrants selected in comparison with those still domiciled? If by selection you mean that migrants do not make up an exact cross-section of the population in a certain area, all cases of socalled free migration can be stated to be selective. A large number of studies, carried out by demographers and sociologists among others, show that age is the most important variable for selection, but that sex, civil status and occupation also have clearly selective characteristics. The problem of selection has, however, largely been treated only in structural terms where the starting-point has been comparison of the composition of migrants and those still domiciled with regard to the variables mentioned, whereas the qualitative aspect, the persona1 characteristics of the migrants, has hardly ever been mentioned, which is probably due to the shortage of relevant source material.

This paper focuses on the problem of the qualitative selectivity of migrants. The research on this subject will, by way of introduction, be described in brief and then followed by a number of hypotheses aiming at explaining on one hand the selectivity regarding the personal characteristics of migrants against the sets of plus and minus factors at places of origin and destination and, on the other, the selectivity of emigrants over time. In connection with these hypotheses, an attempt is made at answering a number of questions starting from a micro-investigation on migration from the agrarian parish of Alfa in Norrland at the time for the sweeping surge of emigration to America during the 19th century. The aim is to find out whether anything points to qualitative selectivity for these migrants and the extent to which the presented hypotheses are correlated with this result. 


\section{Earlier research}

Many investigations have been made in order to find out whether ntelligence is selective for internal migration. One of the earliest eports on this research, where probably the still most detailed liscussion of relevant problems can be found, is Dorothy Swaine Thomas' Research Memorandum on Migration Differentials. The selecion process between various types of societies, principally the ural-urban, is here discussed on the basis of a number of investigaions. Two researchers, Gist and Clarke, have for example studied ntelligence as a selective factor in rural-urban migration and Arawn the conclusion that "those who had migrated to urban areas ad an intelligence quotient slightly (but statistically significantly) iigher than those who remained in rural areas", whereas another "esearcher, Klineberg, who studied Negro children whose parents ad migrated from the Southern States to the cities in the North lid not find any differences in intelligence between migrants and hose still domiciled in the original environment. ${ }^{1}$ Thomas draws he conclusion that the problems have not been sufficiently penerated from an empirical point of view and that most investigations nave statistical errors, due to negligence or to the impossibility of naking significant classifications of the compared groups of populaion. ${ }^{2}$ Apart from the selectivity of age, she does not think that ther generalizations about consistency in different contexts and over longer periods of time can be made for internal migration. ${ }^{3}$

This last opinion is shared by Donald $\mathbf{J}$. Bogue who however, after extensive studies of subregional migration is the U.S. in 1935-40, together with other researchers presented a number of nypotheses about principles of selectivity under more specified conditions. ${ }^{4}$ They trenchantly summed up the current state of snowledge under the heading "An approach to a Theory of Differiential Migration" starting from the hypothesis that internal nigration is highly selective in many different ways but that it may vary in pattern as well as in intensity between different places and periods of time. ${ }^{5}$

It is still an open question whether intelligence is selective with regard to external migration in spite of the many investigations that ave been made, primarily in the U.S. One of the reasons for this nay be that research has been too biased towards intelligence tests of immigrants who usually got lower scores than the indigenous population. Critics maintain, however, that this method is irrelevant or studies of the selectivity of intelligence for the external migrants 
because of the difficulties in constructing "culture-free" tests. The results can thus be due to the differentcultural background of the immigrants. A relevant method will instead be to compare the external migrants with persons who are still domiciled at their places of origin in their home countries. ${ }^{6}$

Different types of migration, internal/external, and very short/ long migrations are generally treated separately. Everett S. Lee made, however, in $1966^{7}$ an attempt to develop a more general diagram with regard to several different types of mobility in which he also strongly stressed the importance of the individual factors. The following four aspects influence, according to Lee, the decision to migrate and thus the whole migration process.

1. Factors associated with the area of origin.

2. Factors associated with the area of destination.

3. Intervening obstacles.

4. Personal factors. ${ }^{8}$

Starting from this model (Figure 1), Lee formulates a number of hypotheses about the volume of migration under changing conditions, about migration streams and counter-streams, and about the personal characteristics of the migrants. The latter include among other things :

\section{Migration factors}

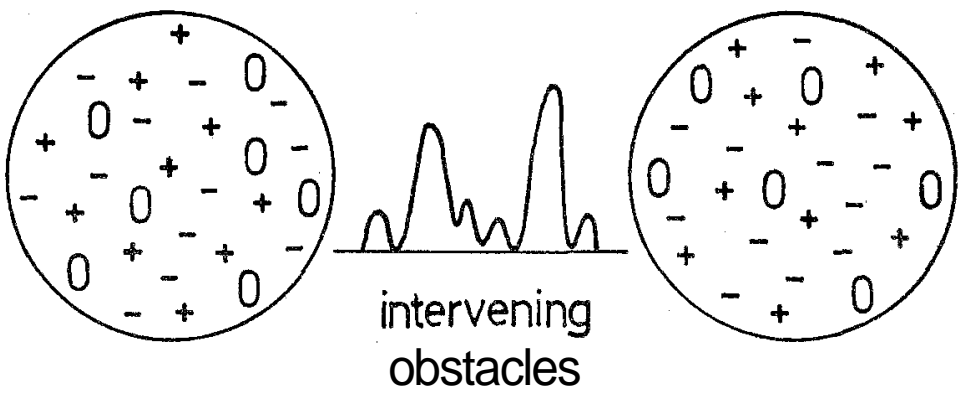

delivering area

receiving area

Figure 1. Migration model by Everett S. Lee.

Source: Everett S. Lee, "A theory of Migration", Demography 3 No 11966. Reprinted in Heer, David, M. (ed.) Readings on Population, New Jersey 1968. 
"Migration is selective"

"The reason why migration is selective is that persons respond differently to the sets of plus and minus factors at origin and at destination, have different abilities to overcome the intervening sets of obstacles, and differ from each other in terms of the personal factors discussed above". ("Personal sensitivities, intelligence, and awareness of conditions elsewhere") ... "The kind of selection, however, varies, being positive in some streams and negative in others. By positive selection is meant selection for migrants of high quality and by negative selection the reverse". . "Migrants responding prima ily to plus factors at destination tend to be positively selected".

"These persons are under no necessity to migrate but do so because they perceive opportunities from afar and they can weigh the advantages at origin and destination".

3. "Migrants responding primarily to minus factors at origin tend to be negatively selected; or, where the minus factors are overwhelming to entire population groups, they may not be selected at all".

"Examples of the latter are political expulsions like that of Germans from Poland and East Prussia or the Irish flight which followed the failure of the potato crop".

4. "Taking all migrants together, selection tends to be bi-modal". "For any given origin, some of the migrants who leave are responding primarily to plus factors at destination and therefore tend to be positively selected, while others are responding to minus factors and therefore tend to be negatively selected".

5. "The degree of positive selection increases with the difficulty of the intervening obstacles". 9

Consideration is thus taken in Lee's model to the influence of both push- and pull-factors on the migration process at a certain point of time. This means that the model on the whole is static in that it does not explicitly express any hypothesis about the development of a migration process over time. An attempt at such an explanatory model regarding the largescale emigration to America was made by Sune Akerman in a report to the Nordic Conference of Historians in Copenhagen in 1971.10

Emigration is, in this model (Figure 2), regarded as a process of innovation, illustrated with the aid of a growth curve divided into various phases. According to this model the emigrants in the first 


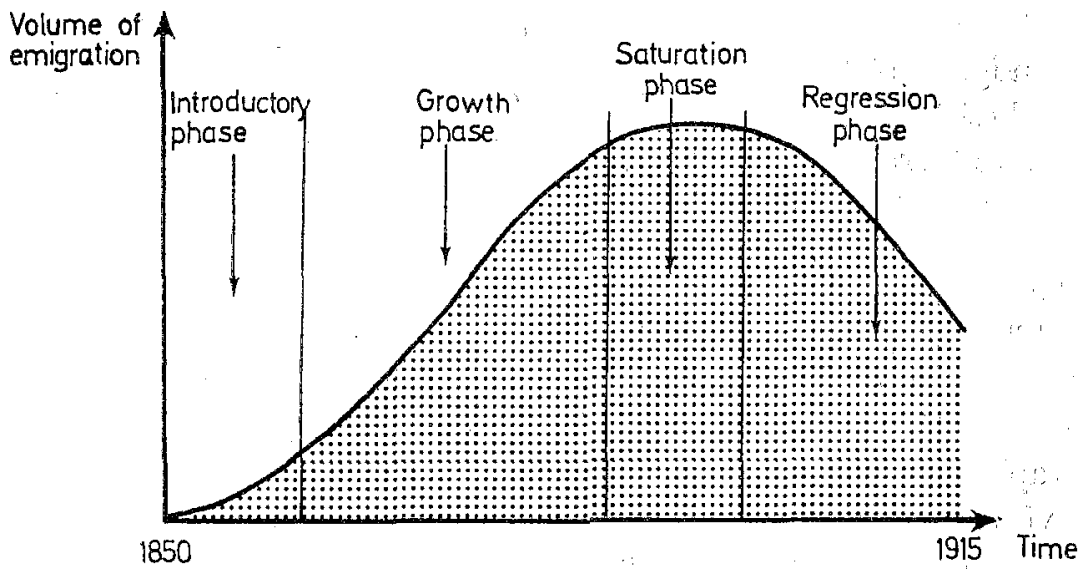

Figure 2. Sune Akerman's model of emigration as a growth process.

Source: Sune Åkerman, "Theories and Methods of Migration Research", in H. Runblom and H. Norman (eds.) From Sweden to America. Uppsala 1976.

emigration phase - the so-called innovators - are very positively selected as regards education, knowledge, and contacts, and often belong to a high social class. A fairly strong positive selection can be expected in the second phase - the growth phase - as well. As the migration process continues and grows into a mass movement, these social differences will be levelled out. This phenomenon is sometimes characterized as "leaders and followers". In the third phase - the saturation phase - the selectivity of occupation and personal characteristics decreases and in the last phase - the regression phase - they sometimes change into negative selection. ${ }^{11}$

\section{Problems}

Starting from the above-mentioned hypotheses about the qualitative selection of migrants, we will try to answer the following questions:

1. Does anything point to qualitative selection of migrants from the parish of Alfta in the emigration periods of the 19th century? (Connected with the first of Lee's hypotheses).

2. Are there any changes over time? For example, are the earlier emigrants more positively selected than the later ones? (Connected with Akerman's hypothesis). ${ }^{12}$

3. Are the migrants in the years of famine in 1866-70 negatively selected or unselected? (Connected with the third of Lee's hypotheses). 
4. How is the selectivity of urban migrants compared with rural migrants? (Connected with Sorokin's and Zimmerman's hypothesis).

5. Are there any tendencies to bimodal selection? (Connected with the fourth of Lee's hypotheses).

\section{Source material}

The source material in the study is made up of original data in the Church examination registers of the parish. These registers are arranged in periods of five years and include on one hand demographic data with names, dates of birth, parish of birth, occupation, civil status, and migrations, $1^{3}$ and, on the other, examination data with other things, marks in reading and comprehension and in memorization of the Holy Scriptures. The individuals are recorded in these registers according to family, house, and village.

The origin of the Church examination registers is primarily connected with the popular education of the Church. It was the duty of the clergymen, according to the Church Law of 1686, to verify the knowledge of the population in the Christian faith and "to find out if they made progress". They also were responsible for seeing that everybody learnt to read from a book. ${ }^{14}$ These checks were made at the yearly Church examinations when the result was noted in the Church examination registers. It seems, however, that preparation for confirmation, in the period of time included in this study, was the most important occasion for distributing marks since the level of marks for groups in the same age cohorts in the material for Alfta in many cases is relatively constant over time. It varies on the other hand with age, sex, landed/landless, and parish of birth in a way where the younger persons tend to have higher marks than the older ones - especially towards the end of the period in this study - women have higher marks than men, landed persons have higher marks than the landless, and persons born in another parish have higher marks than persons born in Alfta.

The marks in reading and comprehension in the Church examinations registers form the basis for the investigation of the qualitative selectivity of migrants from Alfta in 1846-50 and in 1866-95. It can hardly be denied that the proficiencies that the marks set out to measure are important factors for personal characteristics, but at the same time it is also very difficult to judge the extent to which these characteristics are correctly reflected in the marks. ${ }^{15}$ One important consideration here is that the clergymen probably knew 
everybody personally before the first marks were distributed at confirmation. It can also be pointed out that the clergymen served in the parish for considerable periods, ${ }^{16}$ which must have enabled them to follow the progress of their parishioners over a longer period of time and must moreover have provided continuity to the judgements. Against this background it should, therefore, be possible to use the marks as qualitative variables, indirectly conveying something of personal characteristics.

\section{Method}

The method that is primarily used amounts to investigating how the mean of the marks in reading and comprehension for various groups of out-migrants deviates from the mean for corresponding groups who are still domiciled in the same five-year-period. The mean has been calculated on the basis of a marking scale divided into three, starting from the following marks: $1=$ A little, $2=$ Moderate, $\mathbf{3}=$ Passable or better. The comparison includes all individuals aged 15-49 years who have been recorded in the parish at any time during the five-year-period, ${ }^{17}$ and who have marks in both reading and comprehension..$^{18}$ An adjustment has on one hand been made between the wish to include as many migrants as possible in order to avoid too low figures at the division into subgroups and on the other the effort to limit the spread of the ages within the groups compared. The age groups 15-29 and 30-49 years have been used in the comparisons of marks for migrants and the still-domiciled. Consideration has, however, also been taken to differences in the structure of ages within these categories. ${ }^{19}$

The comparisons of the marks for migrants and the still domiciled have been made on the basis of the groups obtained when the variables age, sex, and landed/landless classes successively have been kept constant with, on one hand, reference to everybody in the ages 15-49 years and, on the other, with reference only to persons born in the parish of Alfta. The marks of migrants and the still-domiciled have, moreover, in these two groups been compared with reference to presence at the examinations in each five-year-period. ${ }^{20}$

\section{A micro-investigation of the qualitative selectivity of migrants}

The investigation area is the parish of Alfta in Sweden. ${ }^{21}$ The investigation has been restricted to the periods of $1846-50$ and 
Table 1. Number of out-migrants and emigrants over 15 years of age from the parish of Alfta in 1846-50 and in 1866-95.

\begin{tabular}{lccccccc}
\hline & $1846-$ & $1866-$ & $1871-$ & $1876-$ & $1881-$ & $1886-$ & $1891-$ \\
& 50 & 70 & 75 & 80 & 85 & 90 & 95 \\
\hline Out-migrants & 136 & 151 & 181 & 146 & 193 & 293 & 312 \\
Emigrants & 280 & 229 & 35 & 36 & 252 & 173 & 97 \\
\hline
\end{tabular}

Source: Church Examination Records (husforhorslangder).

1866-95. The choice of investigation area, like the limitation in time, has been made with consideration to, among other things, an extensive emigration from the parish and, for Sweden, a very early tradition of emigration. The first who emigrated, as early as in 1846, were members of a religious sect and were called Erik Janssonites $^{22}$ after their leader. The total number of the emigrants belonging to this sect was around 1200 and 382 of them were from Alfta. The years of crop failure at the end of the 1860's resulted in a new surge of emigration leading to 318 persons leaving the parish during the years of 1866-70. A third sweeping surge of emigration took place in 1881-95 when 682 persons left the parish of whom almost $50 \%$ emigrated as early as in 1881-85. The number of outmigrants and emigrants over 15 years of age is presented in Table 1.

,Selection by Marks of Out-Migrants and Emigrants

The average for migrants from the parish of Alfta in 1846-50 and in 1866-95 in many cases clearly deviate from the average marks for the still-domiciled. Migrants in the ages 15-29 years are, totally, less selected by marks than migrants in the older group, 30-49 years. Especially out-migrants in the latter group are clearly positively selected after 1870 . In the preceding period, however the so-called period of faminein 1866-70 - the average marks agree with those of the still-domiciled. The emigrants in the older age group are positively selected during the first four and negatively selected during the last three of the seven five-year-periods included in the investigation. The younger emigrants are positively selected only in 1876-80. (Figure 4.)

Selection by Marks of Out-Migrants

Age, sex andparish of birth. Out of a total of 1198 out-migrants in the ages 15-49 years in the investigation, only $534^{23}$ were born in the parish of Alfta. Since the average marks for these persons are 
Deviation from the average marks of the still-domiciled

$+0.4$

$+0.2 \Omega$

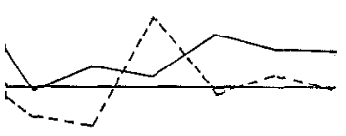

$-0.2$

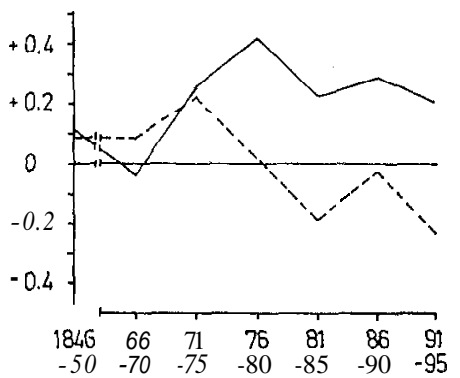

$\begin{array}{rrrrrrr}1846 & 66 & 71 & 76 & 81 & 86 & 91\end{array}$

$\begin{array}{lllllll}-50 & -70 & -75 & -80 & -85 & -90 & -95\end{array}$

$\begin{array}{lllllll}-50 & -70 & -75 & -80 & -85 & -90 & -95\end{array}$

- Out-migrants

- - - Emigrants

Figure 4. Deviation in average marks for migrants from Alfta in 1846-50 and in 1866-95 from those of the still-domiciled (Deviation in absolute terms on a marking scale divided into three).

Source: Church Examination Record (husforhorslangder).

Lower than for persons born in another parish, the curve for the selection of marks has, in several cases, a considerably different xppearance when only persons born in Alfta are compared. A clearly negative selection of marks thus appears in the younger age group $\mathrm{n}$ several periods, especially among women but also among men, sarticularly in the period of famine in 1866-70. The latter are most Jositively selected in 1846-50 but also manifest a peak in 1881-85. The age group 30-49 years shows an overwhelmingly strong positive ielection by marks with the exception primarily for the period of amine in 1866-70. The positive selection culminates in the $1870^{\circ} \mathrm{s}$, whereas women reach the corresponding peak in the later five-yearseriod. (Figure 5.)

Age, sex, and landed/landless classes. The selection by marks has also seen studied with reference to the categories landed and landless :lasses, ${ }^{24}$ by a continuous division of the preceding age and sex :ategories. A pattern thus appears, largely indicating a decreasing ositive selection over time for the landed, whereas the development or the landless is quite the reverse. These tendencies make themelves felt most clearly among men, especially among younger men, 
a)

Deviation from the

averuge marks of the

still-domiciled

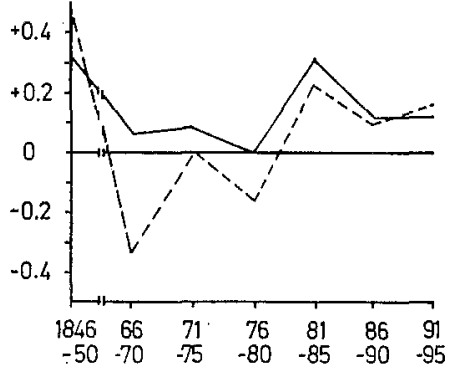

c) Men. 30-49

Deviation from the

average marks of the

still-domiciled

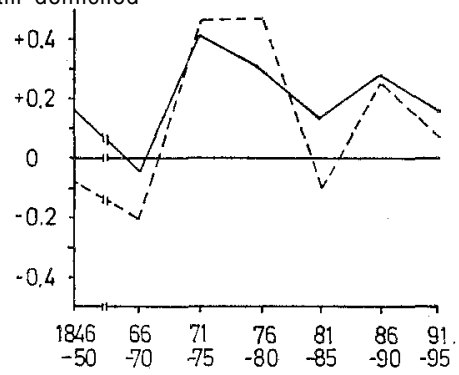

b) Women, 15-29,

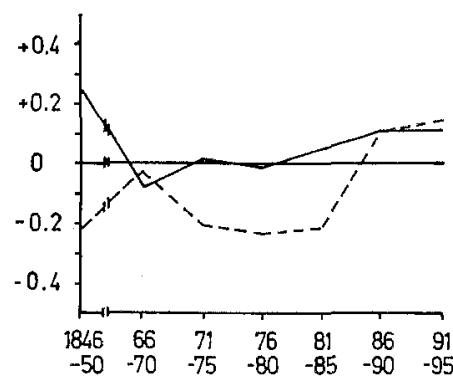

d) Women, 30-49.

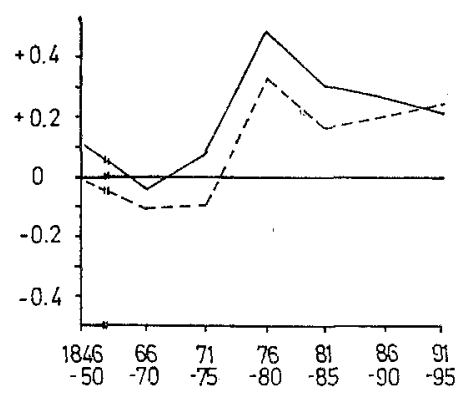

- All

Persons born in the parish of Alfta

Figure 5. Deviation in average marks for migrants from Alfta in 1846-50 and in 1866-95 from those of the still-domiciled.

Source: Church Examination Record (husforhorslangder).

but they also appear among women, at least in the later periods. This pattern is, however, broken in most cases primarily by the period of famine in 1866-70 when most categories of out-migrants show a negative selection by marks. (Figure 6.) ${ }^{25}$

Selection by Marks for Out-Migrants into Towns and Other Rural Areas

Most out-migrants have moved to other rural areas. Only 15.9 per cent have moved into towns. These arc totally very strongly 
Men, 15-29

viation from the

ieroge marks of the

ill-domiciled

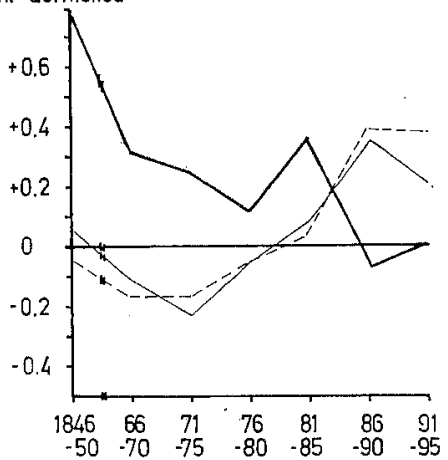

Women, 15-29

eviation from the

verage marks of the

till-domiciled

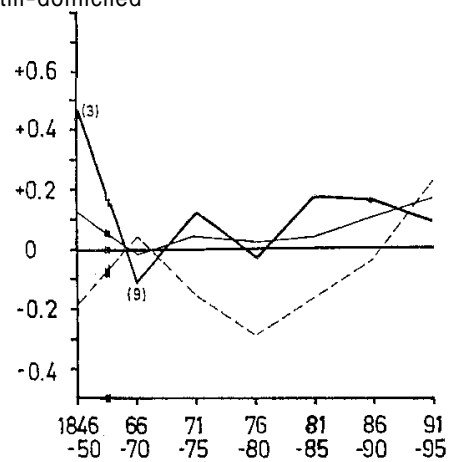

$\longrightarrow$ - All

, ---Persons born in the parish of Alfta

- ---Landless

- - -- Landed

ure 6. Deviation in average marks for landed and landless out-migrants from ta in $1846-50$ and in $1866-95$, in the ages $15-29$ and 30-49 years compared $\mathrm{h}$ those of the still-domiciled. ${ }^{26}$

urce: Church Examination Record (husforhorslangder. 
a) Out-migrants in total $15-49$

Deviation in marks

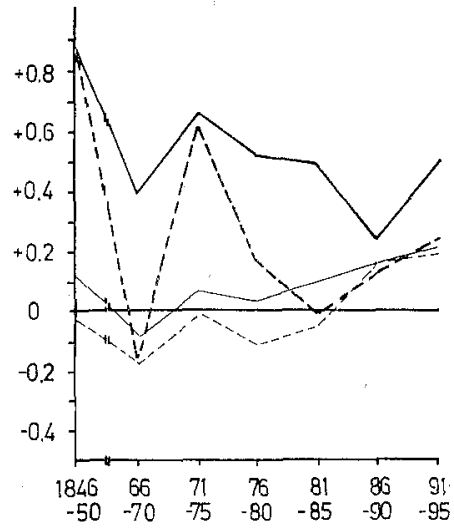

-. - All

- - -,---Persons barn in the parish of Alfta

_. - U Urban migrants

$\longrightarrow$ - - - Rural migrants b) Out-migrants $15-29$

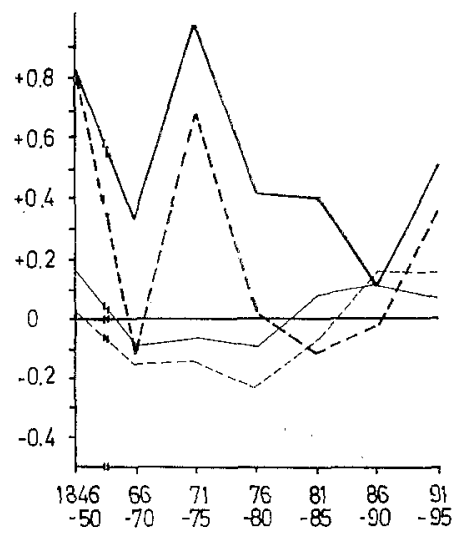

Figure 7. Deviation in average marks for out-migrants to towns and to other rural areas from those of the still-domiciled. ${ }^{27}$

Source: Church Examination Record (husforhorslangder).

positively selected, whereas migrants to other rural areas are almost unselected apart from a positive development in the last periods which leads to a clear decrease in the differences between the two categories. Almost two-thirds of the out-migrants in the ages 15-49 years belong to the age category 15-26 years. 17.6 per cent of these have moved into towns. The selectivity of marks for the two types of out-migrants is largely the same as before but with a more expressed positive "peak" in 1871-75 for the migrants to towns and a clearly larger negative selectivity for the migrants to the rural areas. In spite of this totally very clearly positive selectivity for the migrants into towns, it is, for town migrants born in Alfta, difficult to decide whether there is such a selectivity among them too, since they are not very numerous. Clear tendencies in this direction can only be found in the first and last periods. The urban migrants have, however, lower marks than the migrants to rural areas in the 1880's. \{Figure 7.) 
a) Migrants to rural areas in the age group 15-29 years

Deviation in marks

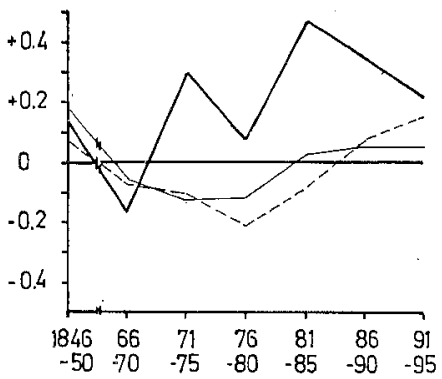

b) Migrants to rural areas in the age group $30-49$ years

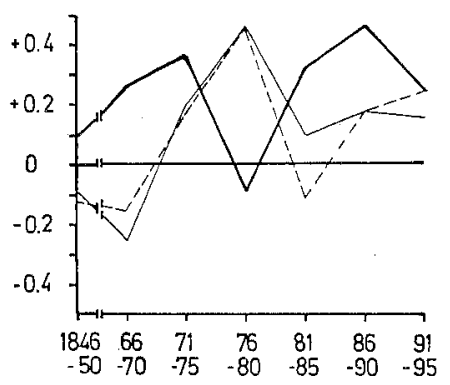

Figure 8. Deviation in average marks for out-migrants to rural areas in the county of Gavleborg (the X-county) and in other counties compared with marks for the still-domiciled. (For absolute terms, see Appendix, Table 1:3.) ${ }^{28}$

Source: Church Examination Record (husforhorslangder).

Selection by Marks of Out-Migrants to Rural Areas in the Home County and in Other Counties

Of those who have moved to rural areas, the ones who have moved to other counties are clearly more positively selected than those who have moved within the same county. The latter are practically unselected in the age group 15-29 years whereas in the older age group they show a strongly varying selectivity ranging from a clearly negative in the period of famine in 1866-70 to a strongly positive in 1876-80. Among the younger migrants to rural areas, those who have moved to other counties are negatively selected only in 1866-70. A negative selection appears, for the older migrants in this category, in $1876-80$, i.e. at the same time as the positive selection reaches its peak for migrants within the county. (Figure 8.)

Selectivity of Marks for the Emigrants

Age, sex, andparish of birth. Of a total of 850 emigrants in the ages 15-49 years, 724 (=85.2 per cent) were born in the parish of Alfta. This leads to a higher correlation for the selectivity of marks for all 
emigrants compared with those for the emigrants born in Alfta than for the out-migrants. The male emigrants in the ages 15-29 years show a slight negative selectivity of marks with the exception of the period 1876-80 when the selection is positive. The female emigrants, on the other hand, show in most periods a slightly positive selection by marks and a negative one only in 1866-75. The emigrants in 1876-80 represent totally, for both men and women, the most

a) Men, $15-29$ years of age

Deviation in marks

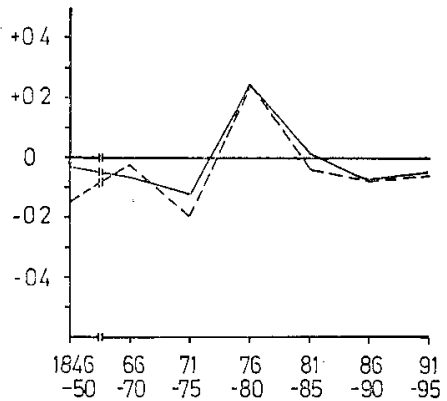

c) Men, 30-49 years of age

Deviation in marks

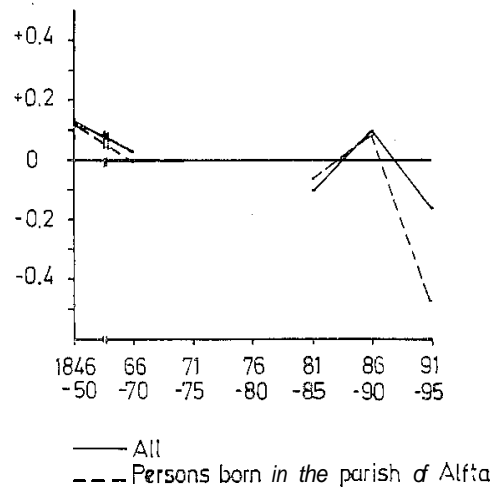

b) Women, 15-29 years of age

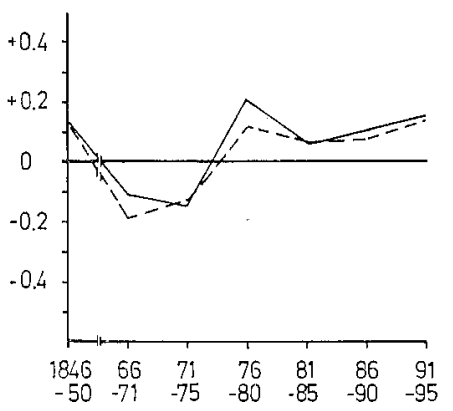

d) Women, 30-49 years of age

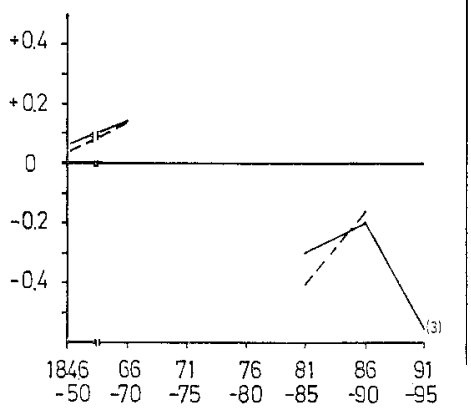

Figure 9. Deviation in average marks for male and female emigrants from Alfta, 15-29, and 3049 years of age, compared with those for the still-domiciled. (Due to the low number of the emigrants in the 1870's - 11 men and 6 women these periods have not been included in figures $9 c$ and $9 d$ ).

Source: Church Examination Record (husforhoi-slangder). 
ositively selected group of emigrants in the ages 15-29 years in all eriods. More than 50 per cent of the emigration in this period took lace in the last year, in 1880, which means that the emigrants who ere positively selected with regard to marks Iargely made up the ry first to emigrate during the 1880's.

There is, as we have earlier pointed out, a change in the trend of ie selection by marks over time from positive to negative. This is lost clearly expressed among women whereas men show a temorary rise in 1886-90. (Figure 9.)

Age, sex, and landed/landless classes. The age group 15-29 years. A ontinued division of the preceding categories into Ianded and ndless classes results, in several cases, in clear differences with gard to the selectivity of marks for the emigrants. This is most istinct for the emigrants in the period of famine during 1866-70, hen the landed tend to be negatively and the landless positively lected. These differences in selectivity are more pronounced for omen than for men in the age group 15-29 years. The negative lectivity of marks of landed women in the period 1866-70 is in tarp contrast to their positive selectivity in the earliest emigration sriods and a clearly positive trend in the last periods. The landless omen at the same time show an insignificantly positive selectivity, sart from a certain increase in 1881-85. Landed men are negavely selected in the first two and the last five-year-periods and iselected in 1881-90, whereas the landless are unselected in actically all periods apart from a negative selectivity in 1886-90. Figures $10 \mathrm{a}, \mathrm{b}$.

The age group 30-49 years. Differences in selectivity between nded and landless in the older age group can primarily be found nong men. These differences can here, too, primarily be discerned uring the emigration in the famine of 1866-70 when the landless tve their highest positive selectivity of marks at the same time as te landed present a strongly negative selection. This situation is, swever, the reverse during the surge of emigration in the 1880's pecially in the first period. The differences in marks increase in all tses if only persons born in Alfta are compared. As for women, the ndless here also show a positive peak in 1866-70 for selectivity of arks, whereas the Ianded are unselected. After this, both cateories have a tendency towards negative selectivity.

These clearly reverse patterns of seiectivity with the landed or the 
a) Men, 15-29 years of age

Deviation in marks

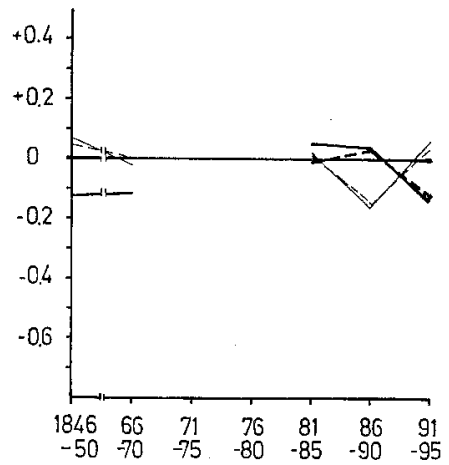

c) Men, 30-49 years of age

Deviation in marks

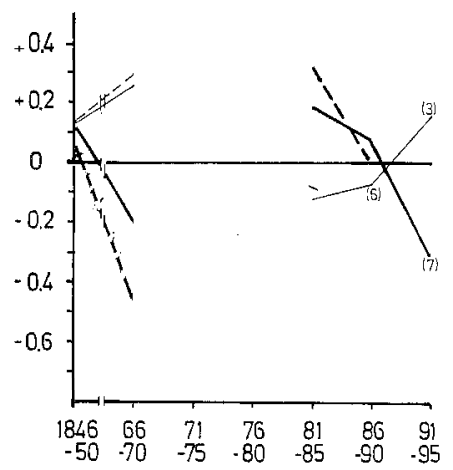

b) Women, 15-29 years of age

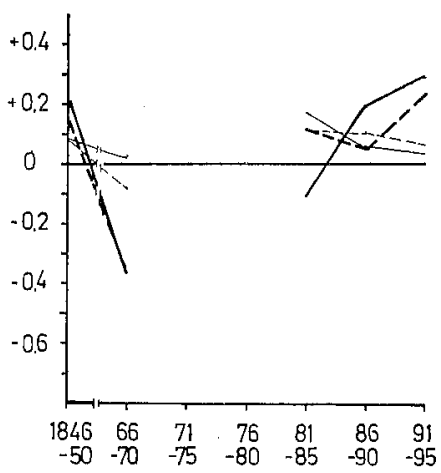

d) Women, 30-49 years of age

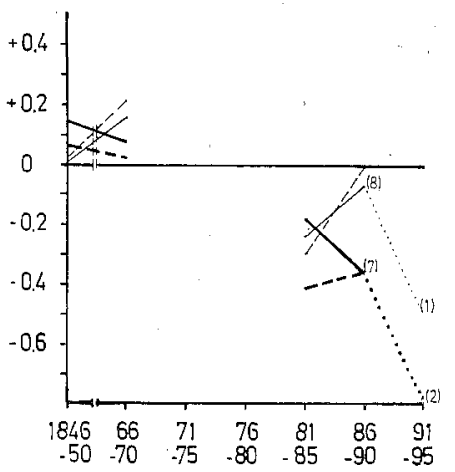

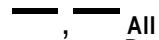

- _, - - Persons born in the parish of Alfta

,---- Landless

- -- -Landed

Figure 10. Deviation in average marks for landed and landless emigrants from Alfta in the ages 15-29, and 30-49 years, compared with those for stilldomiciled. ${ }^{29}, 30$

Source: Church Examination Record (husforhorslangder).

If landless emigrants during the period of famine, deserves some attention. The question is whether we can find a likely explanation to this? 
If we consider it probable that there has been a positive correlaon between the level of marks of the landed - i.e. mainly those of e farmers - and their ability to continue farming during the years famine, a possible explanation of the very negative selectivity of arks of the landed emigrants could be that they had mainly been cruited from a group of farmers who had simply not survived the rain of the years of famine. For many of these farmers the situation ay have been that they had more or less been forced to sell their rms and that emigration to America was the best alternative.

Inversely, the very positive selectivity of marks of the landless nigrants could have resulted from the recruitment, in this case, king place in a higher class of the landless, where there had not ly been a sufficiently strong initiative to emigrate, but also onomic conditions to emigrate (Figures 10c, d).

\section{esults}

\section{he Selectivity of Marks for Migrants}

The migrants from the parish of Alfta generally have a proounced selectivity with regard to marks compared with the rresponding categories still domiciled in the seven five-yeareriods between 1846 and 1895 . The selectivity is largely positive at at the same time shows a comparatively complicated pattern here different tendencies appear according to period of migration, pe of migration - out-migration or emigration - and category of igrants with regard to age, sex, landed/landless classes, and parish birth. The period when the external conditions seemingly have en most influential for the selectivity of marks for the migrants is te period of famine in 1866-70 when most migrant categories show clearly decreasing positive selectivity or a negative selection. As $r$ type of migration, the out-migrants totally have a higher lectivity of marks than the emigrants in several periods, which nong other things is due to the considerably higher proportion of ersons born in another parish where the average marks are higher Ian in Alfta. The selection is more extensive and more often posive in the older age group than in the younger one. It can furtherlore be found for both men and women, landed and landless. then only persons born in the parish of Alfta are compared, a ear decrease of the positive selectivity of marks for the outligrants is found. For younger women it is even clearly negative, 
whereas for older men it has an increasingly positive selectivity in the 1870's. The selectivity of persons born in Alfta is also larger among emigrants in this category. To the extent that the marks can be supposed to reflect something of the personal characteristics of the migrants, it can thus be observed that the result agrees with Lee's hypothesis that migrants are selected in this respect.

\section{Changes in Selection by Marks over Time}

Several different tendencies can be discerned for changes in the selection by marks of migrants. Among the out-migrants, the positive selectivity of the landed tends to decrease, whereas for the landless it passes from negative to positive. As for differences between urban and rural migrants, they tend to be somewhat reduced, which also seems to be true of the differences between rural migrants within the home county and migrants to other counties. Among the emigrants in the younger age group, 15-29 years, there are hardly any tendencies in any certain direction as regards the selectivity of marks in the whole investigation period. If only the large-scale emigration in the 1880's is observed, a certain positive tendency can be discerned for the very young among the first emigrants. The selectivity of marks for emigrants in the age group 30-49 years undergoes, on the other hand, an obvious change from positive in the first emigration periods to an increasingly negative in the following ones with the exception of a certain rise in 1886-90. The hypothesis in Sune Akerman's model that earlier emigrants were more positively selected than later ones, thus proves to be true of the selectivity of marks for emigrants from Alfta in the ages 30-49 years in the fifty-year-period of 1846-95. As for the younger emigrants in the ages 15-29 years, there is an indication of agreement with the hypothesis only in connection with the surge of emigration in the 1880 's. ${ }^{31}$

\section{Selectivity of Marks for Migrants in the Period of Famine in 1866-70}

The migrants from Alfta show a clearly decreasing positive selectivity of marks in the period of famine in 1866-70. This selectivity for persons born in Alfta is almost completely negative. The tendency is strongest among out-migrants but can also be discerned for emigrants. It makes itself felt for both men and women. Pronounced changes in selectivity in a negative direction are almost completely concentrated to the landed, whereas the landless are comparatively unselected in this particular period or may even 
Low a tendency towards positive selection which is very clearly ronounced for emigrants in the age group, 30-49 years. The eason for the landed emigrants being very negatively selected ould be that they have largely been recruited from the landed in le lowest position, while the Iandless emigrants inversely probably elonged to the upper class among the landless as regards initiative nd economic conditions to emigrate.

Lee's hypothesis that migrants who have moved because of ifficult conditions at their places of origin tend to be unselected or egatively selected is thus largely valid for the selectivity of marks or the migrants from Alfta in the period of famine, but is on the ther hand not valid in each individual case as regards the various nigrant categories.

ilectivity of Marks for Urban and Rural Migrants

Among the out-migrants, those moving into towns are, totally, onsiderably more positively selected than migrants to other rural reas. Persons who have moved to other counties are, among the itter, more selected than those who have moved within the same Junty. These differences are, however, clearly reduced when only ersons born in Alfta are compared. Because of the too low number f town migrants among them in certain periods, it is not possible draw any general conclusions from such differences between rral and urban migrants among out-migrants born in Alfta.

\section{endencies to Bimodal Selectivity}

Neither out-migrants nor emigrants manifest any larger extent E bimodal selectivity of marks. In the category "persons born in lfta" only emigrants in the period of 1846-50 have larger proporons of low and high marks than the still-domiciled on the scale ivided into three. These differences do not, however, make up lore than one and a half per cent. On the other hand, for the eriod of 1881-85 the emigrants have a larger proportion (9.5 per snt) of low marks than the still-domiciled at the same time as the roportion of high marks is only 1.7 per cent lower. Bimodal tenencies also occur to a larger extent in this period than in other eriods among different emigrant categories. A clearly bimodal :lectivity can, among other things, be discerned for a group of tndless men in the age group 30-49 years. Tendencies towards imodal selection can also be observed in other periods, primarily ir the landless and especially for women in the ages 15-29 years 
who at the same time show a relatively low degree of selectivity. Lee's hypothesis about a tendency towards bimodal selectivity for migrants is thus only partly correct. The strong tendency towards bimodal selectivity of marks for some emigrant categories in the period of 1881-85, which in this case can be seen as the equivalent of the "saturation phase" in Åkerman's model, indicates moreover that totally, a low selectivity among different emigrant categories in this phase can partly be the result of increasing bimodal tendencies primarily through larger portions of negatively selected emigrants.

\section{Comments}

The results for the selectivity of marks for the migrants from Alfta can of course be commented upon and discussed from many points of view. Only three points which have been considered capable of influencing the results will be taken up here. They are a) in some cases the low absolute terms, b) the religious conflicts of the earliest emigrants - the so-called jansonites - with the Church, and c) the possible dependence of the marks of Church -attendance with reference to presence at the examinations. As for the problem with the low absolute terms it recurs now and then in the investigation but it is particularly large lor older emigrants in the lastfive-year-period. It could, however, probably be maintained that this applies more to details in the investigation than to the main result since these tendencies mostly have been observed on both an earlier "level" with higher absolute terms and in the preceding periods. The main results remain even apart from the cases where the absolute terms are very low. The emigrants in the first period, in 1846-50, the so-called jansonites, make up a very special problem because of their very strong religious conflicts with the Church. Since these conflicts actually caused the emigration, it cannot be overlooked that this situation may have had a certain negative effect on their level of marks, which means that they might have been more positively selected in reality than can be seen from the result. The presence at the examinations is finally also important if the marks have changed in connection with the Church examinations. This is particularly true of the last two periods when a rapidly decreasing presence can be noted. ${ }^{32}$ Those who have not been present at any examination in the five-year-period have, among the still-domiciled, somewhat lower marks than others, with the exception of the first two periods. Decisive differences for the selectivity 
of marks for the migrants have, however, not been observed when only individuals who have attended the examinations in every period have been compared. The tendencies in the earlier result have in several cases been further strengthened. This is, for example, true of the reverse tendency for the selectivity of marks for landed and landless male emigrants in the ages 30-49 years in the period of famine in $1866-70$.

\section{Summary}

The main theme of this paper has been the qualitative selectivity of migrants. A number of hypotheses about individual characteristics of migrants under specified conditions at the places of origin and destination (Lee) and a hypothesis about changes in selectivity over time for emigrants to America ( $\AA$ kerman), and a hypothesis about differences in selectivity between urban and rural migrants (Sorokin and Zimmerman) have formed the bases for problems in a microinvestigation on migrants from the parish of Alfta in Norrland in $1846-50$ and in 1866-95. The aim has been to explore whether these migrants are qualitatively selected in comparison with the stilldomiciled. The source material has been obtained from the Church examination registers in the parish where the mean of the marks in reading and comprehension has been used as a qualitative variable. Different migrant categories - out-migrants and emigrants of varying age, sex, landed/Iandless classes, parish of birth, and Church attendance - have been compared with the corresponding categories of the still-domiciled and been found as somehow selected by marks with regard to each of these factors separately as well as all combined with each other.

To the extent that the assumption that these marks reflect personal characteristics is correct, it can be said about the problems:

1. that migrants from Alfta in 1846-50 and in 1866-95 have shown a qualitative selectivity in relation to still-domiciled. (The hypothesis is correct.)

2. that emigrants in the ages $30-49$ years have a tendency towards decreasing positive selectivity over time, whereas younger emigrants do not have any definite long-term tendency. (The hypothesis is true of emigrants in the ages 30-49 years but not of younger emigrants in the ages 15-29 years.)

3. that migrants from Alfta in the period of famine in 1866-70 tend to be unselected or negatively selected with the exception of 
landless emigrants in the ages 30-49 years who, on the contrary, show a positive tendency. (The hypothesis is true with the exception of the last statement.)

4. that the urban migrants are totally more positively selected than the rural ones and that the migrants to rural areas in other counties are more positively selected than the migrants moving to rural areas within the same county, but that these differences seem to be reduced when only persons born in Alfta are compared. (The hypothesis about the positive selectivity of urban migrants is largely true, The number of urban migrants born in Alfta is, however, too low for conclusions in the latter case.)

5. that tendencies towards bimodal selectivity do not occur to any larger extent. (The hypothesis is only true to a limited extent.)

The conclusion is thus that there are strong indications that the migrants from the parish of Alfta in 1846-50 and in 1866-95 compared with the still-domiciled were a qualitatively selected category, for whom the pattern of selectivity in certain cases illustrates a relationship between combinations of characteristics for migrants and positive or negative conditions at the places of origin and destination. The fact that the result in important aspects agrees with the results of other research in this sphere could probably be taken as an indication of the validity of the result even outside the time and space limitations of this study. Much research work is however probably required before a more general answer can be given to the problem of the qualitative selectivity of migrants.

\section{Appendix}

Table 1:1. Number of out-migrants from Alfta in 1846-50 and in the age groups 15-29 and 30-49 years, related to sex and landed/landless classes.* ( $\mathrm{M}=$ male, $\mathrm{F}=$ female).

\begin{tabular}{|c|c|c|c|c|c|c|}
\hline $\begin{array}{c}846- \\
50\end{array}$ & $\begin{array}{c}1866- \\
70\end{array}$ & $\begin{array}{c}1871- \\
75\end{array}$ & $\begin{array}{c}1876- \\
80\end{array}$ & $\begin{array}{c}1881- \\
85\end{array}$ & $\begin{array}{c}1886- \\
90\end{array}$ & 9 \\
\hline $1 \mathrm{~F}$ & $\mathrm{M} \mathrm{F}$ & $\mathrm{M}$ & $M F$ & $M F$ & $\mathrm{M} \mathrm{F}$ & $\mathrm{M}$ \\
\hline
\end{tabular}

$15-29$ years

$\begin{array}{lllllllllllllll}\text { Landed } & 10 & 3 & 15 & 9 & 17 & 12 & 13 & 23 & 23 & 22 & 40 & 33 & 56 & 30 \\ \text { Landless } & 22 & 43 & 19 & 30 & 14 & 45 & 20 & 36 & 13 & 47 & 24 & 55 & 26 & 61\end{array}$

30-49years

$\begin{array}{lrrrrrrrrrrrrrr}\text { Landed } & 6 & 4 & 16 & 8 & 17 & 8 & 8 & 14 & 18 & 14 & 22 & 23 & 24 & 25 \\ \text { Landless } & 7 & 17 & 14 & 16 & 13 & 21 & 7 & 9 & 12 & 15 & 26 & 23 & 19 & 26\end{array}$

Source: Church Examination Records (husforhorslangder).

* With marks in both reading and comprehension. 
Table 1:2. Number of urban and rural migrants in the age group 15-29 years from the parish of Alfta in 1846-50 and in 1866-95.*

\begin{tabular}{lccccccc}
\hline & $1846-$ & $1866-$ & $1871-$ & $1876-$ & $1881-$ & $1886-$ & $1891-$ \\
& 50 & 70 & 75 & 80 & 85 & 90 & 95 \\
\hline Rural migrants & 56 & 59 & 77 & 68 & 75 & 124 & 153 \\
Urban migrants & 17 & 13 & 10 & 24 & 21 & 27 & 19 \\
\hline
\end{tabular}

Source: Church Examination Records (husforhorslangder).

Table 1:3. Number of rural migrants within the county of Gavleborg (=the X-county) and other counties from Alfta in 1846-50 and in 1866-95.*

\begin{tabular}{lccccccc}
\hline & $1846-$ & $1866-$ & $1871-$ & $1876-$ & $1881-$ & $1886-$ & $1891-$ \\
& 50 & 70 & 75 & 80 & 85 & 90 & 95 \\
\hline 15-29years & & & & & & & \\
X-county & 42 & 48 & 64 & 58 & 65 & 97 & 133 \\
Another county & 14 & 11 & 13 & 10 & 10 & 27 & 19 \\
& & & & & & & \\
$30-49$ years & 18 & 35 & 38 & 22 & 39 & 63 & 65 \\
X-county & 13 & 10 & 12 & 7 & 12 & 17 & 20 \\
Another county & & & & & & &
\end{tabular}

Source: Church Examination Records (husforhorslangder).

Table 1:4. Number of emigrants from the parish of Alfta in 1846-50, 1866-70 and in 1881-95 in the age groups 15-29 and 30-49 years, related to sex and landed/landless classes. ${ }^{*}$ ( $\mathrm{M}=$ male, $\mathrm{F}=$ female $)$.

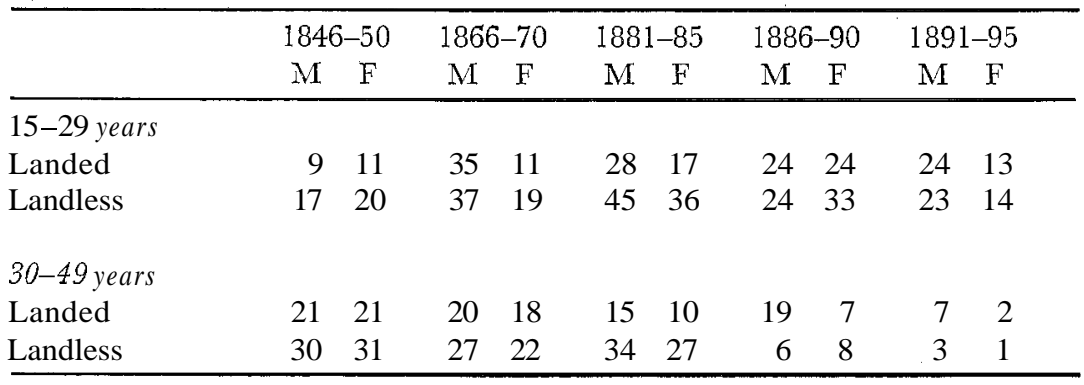

Source: Church Examination Records (husforhorslangder).

* With marks in both reading and comprehension. 


\section{NOTES}

I Thomas, D. S. Research Memorandum on Migration Differentials. New York (1938) Sorokin and Zimmerman formed, as early as in 1929, the hypothesis that "cities attract the extreme while the farms attract the mean strata in society." (Petersen, W. Population, London 1969, p. 272). In a study of the migration from country to town in Sweden in 1942-1956, where the material among other things was made up of school marks and military intelligence tests in a sample (10\%) of the male population born 1928 in Sweden, E. Neymarlr states that "there is a certain connection between migration tendency and marks" and that "the rearrangement of intelligence has been most favourable for the cities". (Newmark, E. Selektiv rorlighet, Stockholm 1961, pp. 222, 190).J. Wallander, who has investigated migration from the region around Klaralven in Sweden, reaches much the same results: "The conclusion is thus that there are strong indications that the more talented move into cities and communities". (Wallander, J. Flykten frain skogsbygden, Stoclrholm 1948, p. 192). The same is true of the American researchers Browning and Feindth who studied migrants into the rapidly growing Mexican city Monterrey in 1940-1946, and who summarize their results as follows: "In general, migrants are positive selective of the population from which they originate.... The second major finding is that migrants have become increasingly less selective over time, with the more rural and backward zone accounting for this overall decline". (Demography 1969 p. 355).

2 The minimal requirement is, according to Thomas, "classification by age, sex, family status, marital condition, occupation and income, distance spanned, type of community of origin and destination and the phase of the business cycle." (Thomas, D. S. Selective Internal Migration, Some Implicationsfor Mental Hygiene. Spengler and Duncan: Demographic Analysis, Glencoe, 1956, p. 430).

3 "Migration may, under given circumstances, select the intelligent; under other circumstances the less intelligent; and under stiil other circumstances be quite unselective with regard to intelligence." Thomas (1938) p. 125.

4 I.e. different conditions at places of origin and destination.

5 Bogue maintains against this background that "The search for migration differentials, then, should be an effort to discover in what ways and why migration was selective of persons with particular characteristics or combinations of characteristics under varying combinations of conditions at origin and conditions at destination." The results also clearly supports the theory that selectivity changes with the age of the migrants. This leads Bogue to the conclusion that "In general, young migrants are selected primarily along the lines of long-run basic differences and imbalances in the social and economic organization, whereas adults are selected, in addition and to a greater extent, with respect to current personal and social problems and current social changes." (Bogue, D. J. Principles \& Demography, New York 1969, pp. 793797).

6 Petersen, Op. cit., p. 271.

7 Lee, E. S. A Theory of Migration, Demography (1966) pp. 47-57. (Reprinted in Heer, D. M. ed, Readings on Population, New Jersey 1968).

8 Lee (1968) p. 184.

9 Op. cit., pp. 191-192.

10 Akerman, S. Intern befolkningsomflyttning och emigration. Rapporter til det nordiske historikermøde i København (1971), pp. 62-72.

11 Akerman, S. From Stockholm to San Francisco, Uppsala (1975), pp. 44-45; Norman and Runblom (ed.), From Sweden to America, Uppsala (1976), pp. $25-32$. 
12 Also connected with Lee's fifth hypothesis.

13 The valuable demographic information in the Church examination registers was used as the basis for the Swedish population statistics when the Old Swedish Central Bureau of Statistics was set up in 1749. Many researchers, among them Sture Martinius, regard the Church examination registers as the most trustworthy source for research on migration. (Martinius, S. Befolkningsrörligheten under industrialismens inledningsskede $i$ Sverige, Goteborg 1967, pp. $36 \mathrm{ff})$.

14 Johansson, E. En studie med kvantitatiua metoder av folkundervisningen $i$ Bygdea socken 1845-1863. Unpublished dissertation at the University of Umeå (1972), p. 16.

15 For reading marks, see B. Odén: Läskunnighet och samhällsförändring, Forskning om utbildning 1975:1 and the discussion between B. Odén and E. Johansson in the same journal 1975:3. At least three factors are, according to E. Johansson, included in the mark for comprehension. Comprehension indicates on one hand a judgement of the deeper knowledge of the Holy Scriptures (memorization), and comprehension is also on the other hand connected with reading comprehension, at the same time as it is closely connected with an estimation of the "natural gifts" and with some kind of "judgements of talent". (Translation of the quotation). Johansson, $O p$. cit., p. 100.

16 Over a period of about one hundred years (1791-1897) the two incumbencies in the parish were occupied by only nine clergymen (five vicars, and four assistant vicars). This corresponds to an average period of service of approximately 23 years. Ohlsson, J. Ur Alfta sockens historia, Malung (1967) pp. 2344.

17 This means that 84.5 per cent of the total number of out-migrants over 15 years of age are included in the investigation of the years 1866-95. The corresponding figure for the period of 1846-50 is as low as 66.4 per cent, due to the fact that a comparatively large number of the emigrants were older than 49 years of age and many young persons had not yet been given marks in comprehension in 1846 when the main part of the emigration took place.

183.6 per cent of the still-domiciled and 6.6 per cent of the out-migrants lack either one or both of the marks for the period of 1866-95 and are therefore not included in the investigation. The corresponding figures for the period of 1846-50 are 6.1 and 21.1 per cent. The reason for the latter figure being so high is the same as in the previous note.

19 The marks of, for example, emigrants in the ages 30-49 years are thus compared with the marks for a category of still-domiciled with the same percentage of persons in the ages 30-39 and 40-49 years. The same is true of the out-migrants. The "weighting" in the younger age group has been made so that the percentage of persons in the ages 15-19 and 20-29 years coincide.

20 The computer work has been carried out at the Data Centre of Umeå (UMDAC) with the aid of the SPSS-subprogramme "BREAKDOWN". Norman, H. N. (and others) SPSS Statistical Packagefor the Social Sciences, New York (1975), pp. 249-264.

21 The parish is situated in the central part of the county of Gavleborg, about sixty kilometres from the coast, bordering on the county of Kopparberg in the south (Figure 3). The population amounted to 4043 persons in 1850 and increased to 5181 in 1895 in spite of a negative migration net. The main part of the population lived on farming and forestry. No industrialization had yet been initiated at the turn of the century. The development of forestry in Norrland and railway construction had, however, provided increasing possibilities of employment for the population since the 1870's. (Emigrationsutredningen. Betankande p. 457). A report from the parish authorities of Alfta to the Commission on Emigration states, among other things, that: "It has hardly been necessary for anybody to emigrate from 
Alfta because of poverty since highly paid work has been available." (Emigrationsutredningen, Appendix 17, p. 177).

22 The doctrine of Erik Jansson meant among other things that when a person once had been absolved from his sins, he could no longer commit new ones. He burnt books by Luther and other religious leaders and gradually became involved in conflict with the Church. The continuous actions against him from the authorities gradually led to the decision of the whole sect to emigrate to America where there was freedom of religion. Herlenius, E. Erikjansismen i Suerige, Uppsala (1897) pp. 16-17.

2344.6 per cent.

24 The landed classes include farmers, craftsmen, officials, and civil servants. The landless classes include crofters, soldiers, workers, farm-hands, and maid-servants.

25 The selectivity of marks for "Born in Alfta" have not been included for all categories of out-migrants as certain periods have absolute terms that are too low (when the absolute term in other cases is lower than ten, this will be indicated by numerals within parentheses).

26 For absolute terms, see Appendix, Table 1:1.

27 Figure b. A continued division shows that the selection by marks of urban migrants like their difference in marks in relation to rural migrants, are totally larger for male than for female migrants. (For absolute terms see Appendix, Table 1:2).

28 The diagrams apply to all rural migrants. Of those who have moved to other counties only 28.6 per cent were born in Alfta, which results in absolute terms that are too low for an analysis of this category.

29 For absolute terms, see Appendix, Table $1: 4$.

30 For absolute terms, see Appendix, Table 1:4.

31 This statement is however of some interest against the background of an increasing number of sole emigrants and a lower average age in connection with the emigration in the 1880's compared with earlier periods, which must mean that there is a larger proportion of persons in the ages 15-29 years who themselves have taken the decision to emigrate. (Theimportance of separating "active" from "passive" migrants is stressed by, among others, Hagerstrand, T. in Hannerberg, D. (ed.), Migration in Sweden, Lund (1957), p. 132.

32 The decrease of the registered presence at the Church examinations is shown by the following figures:

Still-domiciled who have been

$46-50 \quad 66-70 \quad 81-85 \quad 86-90 \quad 91-95$
present at the examinations in each period: $(\%)$.

$89.2 \quad 84.7 \quad 77.3 \quad 66.7$

